\title{
ENA ENA

\section{President}

Peter Prock, Basel

\section{Board Members}

Philip C. Calder, Southampton Manfred Lamprecht, Graz Frantisek Safarik, Basel

Gerald Tulzer, Linz

\section{Advisory Board}

Fabrizia Bamonti, Milano Aalt Bast, Maastricht Wilfried P. Bieger, Munich lain L.C. Chapple, Birmingham Kurt Hecher, Hamburg Johannes Holdhaus, Vienna Johannes Huber, Vienna Michael Kunze, Vienna Gilbert Mertens, Mainz Claudia Reinke, Basel Werner Seebauer, Frankfurt/Oder Jörg Spitz, Frankfurt/Main

\section{Aims and Scope}

The European Nutraceutical Association (ENA) is a specialist association devoted to promoting scientific discussion on Nutraceuticals.

The term Nutraceuticals is an umbrella term for various food products such as dietary supplements or functional food, but also certain specific nutrients. Since they share special health-promoting effects, these products play a role both in prevention and as therapeutic add-ons.

Nutraceuticals are today the subject of intensive discussion in professional circles. With its activities, the ENA would like to contribute to an assessment of this product group on the basis of scientific criteria.

Therefore, the central concerns of the ENA include the organisation of conferences and continuing education courses for nutrition experts in the fields of prevention and health promotion. We also initiate and support research projects with Nutraceuticals. We award a research prize at our Annual Conference every year.

Our official journal is Annals of Nutrition \& Metabolism.

Furthermore, the activities of the society contribute toward generating facts for drawing up a meaningful regulatory framework for these products.

For more information please visit our website:

\section{www.enaonline.org}

\section{Membership}

Membership enquiries should be directed to:

European Nutraceutical Association

Centralbahnstrasse 7

P.O. Box 253

$\mathrm{CH}-4010$ Basel

Switzerland

Phone: +41613020490

Fax: $\quad+41613020491$

Email: office@enaonline.org 